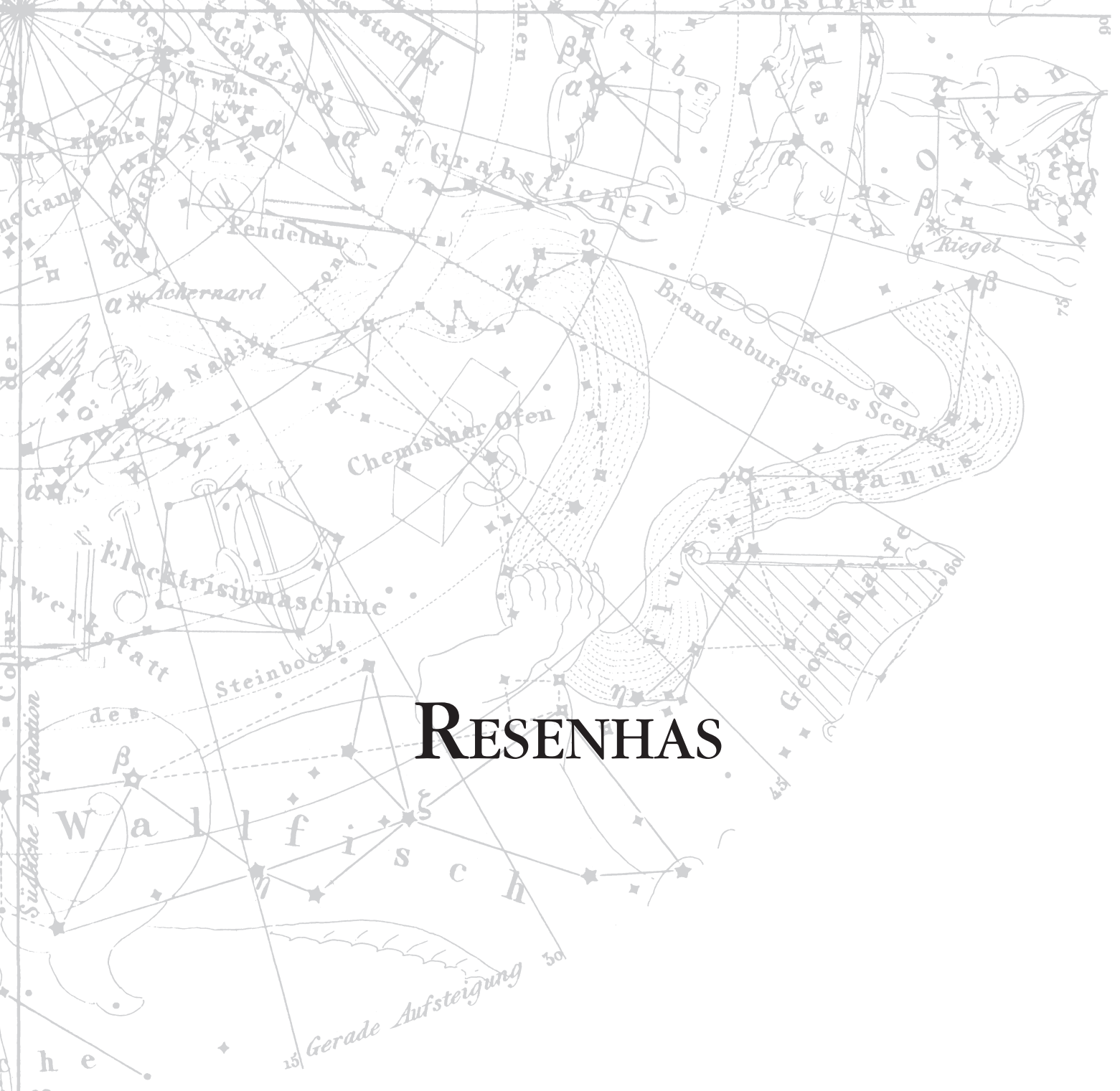





\title{
Estampas do imaginário: literatura, bistória e identidade cultural, de Eneida Leal Cunha
}

\author{
DÉBora LeITE DAVID \\ Universidade de São Paulo
}

uando pensamos em questões historiográficas e canônicas, buscamos invariavelmente um horizonte bem definido e absolutamente cristalino. Essas circunstâncias, dirão alguns, são basilares para o empreendimento de um projeto científico acerca do campo literário. No entanto, as trepidações teóricas que abalaram as ciências humanas como um todo durante o século XX, principalmente na sua segunda metade, trouxeram a esse mesmo horizonte variadas reflexões, no sentido de questionar algumas certezas e reforçar outras tantas dúvidas presentes no pensamento contemporâneo.

Com o advento do Estado moderno, a partir da consolidação das fronteiras nacionais, em meados do século XIX, iniciaram-se amplas discussões a respeito das culturas e das identidades nacionais, porém, intimamente ligadas à política. Esse momento, que consideramos como um marco que delimita a historiografia literária antes e depois da construção da literatura nacional dentro do Estado moderno, é relevante também nos territórios colonizados, ainda que de modo peculiar. Para refletir acerca das expressões culturais produzidas nesses espaços, são imprescindíveis considerações relativas ao escravismo e à colonização. No entanto, com o fortalecimento da globalização e o enfraquecimento das fronteiras nacionais na segunda metade do século $\mathrm{XX}$, vimos o surgimento de pensamentos críticos em oposição à concepção da literatura sempre atrelada à História e ao conceito da nacionalidade. Essa circunstância impulsionou a demanda por novos instrumentos teóricos e críticos que pudessem abarcar sutilezas nos mais diferentes contextos, como as que permeiam as literaturas latino-americanas ou as africanas pós-coloniais, por exemplo.

É nesse passo que surge entre a crítica literária brasileira o livro de ensaios Estampas do imaginário: literatura, história e identidade cultural, de Eneida 
Leal Cunha, professora titular de Literatura Brasileira na Universidade Federal da Bahia. Esses ensaios reunidos representam mais um precioso título lançado pela editora da Universidade Federal de Minas Gerais, que permite ao leitor o acesso às recentes e inovadoras produções em diversas áreas de conhecimento, notadamente dos estudiosos da teoria e da crítica literárias.

Nesse volume deparamos com a leitura crítica de alguns textos escritos entre os séculos XVI e XVIII e relevantes à historiografia literária brasileira. De certo modo, esses textos estão incluídos no acervo literário brasileiro, ainda que considerados à margem do cânone literário nacional consolidado a partir do século XIX. Sob a luz de alguns pensadores como Sigmund Freud, Friedrich Nietzsche, Michel Foucault e Jacques Derrida, além das reflexões de teóricos como Antonio Candido, Roberto Schwarz e Silviano Santiago, a ensaísta constrói um pensamento crítico a respeito da força das determinações e das significações imaginárias na instituição do simbólico. Assim, são apresentados e discutidos os textos "Carta", de Pero Vaz de Caminha, História do Brasil 1500-1627, de Frei Vicente do Salvador, "À Ilha de Maré", de Botelho de Oliveira (poemas, 1705), "Descrição da Ilha de Itaparica", de Manuel de Santa Maria Itaparica (1769), "Caramuru", de Santa Rita Durão (1781) e Viva o povo brasileiro, de João Ubaldo Ribeiro (1984), como acontecimentos discursivos que não apresentam o empenho em construir a nacionalidade literária brasileira, porque elaborados antes ou depois do momento histórico em que esse empenho se tornou mais evidente.

Sob esse título, encontramos coligidos os ensaios "Paul-brasil, bárbaro e nosso", "As aves que aqui gorjeiam", "A fé, o Império e as terras viciosas", "O imaginário brasileiro entre a genealogia e a História" e "A estampa originária da dependência", que derivam da tese de doutorado apresentada pela autora à Pontifícia Universidade Católica do Rio de Janeiro, em 1993. É por meio desses ensaios que a autora coloca o leitor diante dos textos mencionados como "estranhos" ao processo de consolidação da literatura brasileira, para então discutir sobre a problematização das produções de um imaginário formado muito antes dessa consolidação.

$\mathrm{Na}$ breve apresentação elaborada pela própria autora, vislumbramos uma síntese dos aspectos teóricos e críticos abordados ao longo dos textos. Temos também a exposição dos objetivos da organização dessa coletânea que remete ao destaque dos espaços literários marginais no âmbito das reflexões 
contemporâneas acerca da historiografia literária no Brasil. Assim, na tentativa de consolidar um novo paradigma na reflexão sobre as produções do imaginário, as significações do país como traços que se repetem sempre diferenciados, apresenta-se uma apreciação sobre a identidade cultural brasileira, considerada desde as representações do país no imaginário colonizador. Esses traços repetidos, "estampas originárias", seriam como uma matriz para a singularidade nacional, encontrados em exemplares sucessivos do acervo literário brasileiro.

O primeiro ensaio, "Paul-brasil, bárbaro e nosso", começa por aquele que Capistrano de Abreu considera "o primeiro brasileiro conhecido que escreveu prosa num gênero literário", Frei Vicente do Salvador. A partir da leitura de sua obra, História do Brasil (1627), a autora nos apresenta traços apontados e deplorados pelo religioso que ultrapassam a fronteira do relato histórico. Com a narração das peculiaridades que identificavam as posturas e os valores degradados dos povoadores do Brasil, Frei Vicente Salvador aponta traços que estarão por muito tempo no imaginário social brasileiro. E a possibilidade de diálogo entre a contemporaneidade e seus textos e a obra seiscentista demonstra como as significações imaginárias ultrapassam as fronteiras da funcionalidade na determinação do simbólico.

A seguir temos o ensaio "As aves que aqui gorjeiam", em que se encontra a leitura dos poemas "À Ilha de Maré - Termo da Cidade da Bahia" (1705), de Manuel Botelho de Oliveira, e "Descrição da Ilha de Itaparica" (1769), de Frei Manuel de Santa Maria Itaparica, por meio das considerações críticas de Sérgio Buarque de Holanda em Capitulos de literatura colonial. Nesse ensaio a autora propõe a releitura dos poemas com o foco voltado para as articulações possíveis com o texto colonizador: Os Lusíadas, de Luís de Camões. Dessa forma, com a visão da terra a partir de uma correção do valor da colônia no imaginário lusitano, encontramos a tentativa de apaziguamento do imaginário colonizado: a convivência ideal entre o elogio da conquista (valorização da ancestralidade), a irrelevância do Brasil (negligência em relação ao descendente) e a consciência da nova terra (desejo filial de reconhecimento). $\mathrm{Na}$ perspectiva freudiana do "romance familiar", temos o enaltecimento da figura do pai (colonizador) ao mesmo tempo em que se altera ou corrige a falta de importância que o descendente (colonizado) vivencia. 
O ensaio "A fé, o Império e as terras viciosas" nos fala a respeito do poema épico de Santa Rita Durão, o Caramuru, e sua declarada familiaridade com o épico lusitano. Numa leitura comparativa e minuciosa entre os poemas de Santa Rita Durão e Luís de Camões, as considerações se estendem até o século XX, nas retomadas "antropofágicas" de José de Alencar, Gonçalves Dias e Oswald de Andrade. Por meio da ambigüidade e da diferença que permeiam o poema colonial, a autora reflete acerca da repetição de $O s$ Lusíadas e da aderência ao imaginário imperial como fatores de estímulo à "desleitura", produzindo-se assim uma "crítica antitética", no lugar do silêncio defensivo ou da condenação sumária do texto colonial.

$\mathrm{Na}$ seqüência, temos o ensaio "O imaginário brasileiro entre a genealogia e a História", em que a autora nos surpreende com um romance brasileiro contemporâneo: Viva o povo brasileiro, de João Ubaldo Ribeiro. De início temos uma questão polêmica quanto ao gênero da obra, que é negada peremptoriamente pelo escritor como sendo um romance histórico. A partir dessa negativa, que ocorreu antes mesmo da publicação do romance, a autora reflete sobre as transformações do discurso histórico, que passou a incorporar o questionamento, a desconstrução e o descentramento, assim como sobre as referências encontradas no texto de João Ubaldo Ribeiro que remetem ao simbólico institucionalizado. Desta feita, já não importam os valores e as representações produzidas pelo imaginário colonizador, como vimos em Frei Vicente do Salvador, Botelho de Oliveira ou Santa Rita Durão, mas, sim, o imaginário colonizado instituído ao longo da história, seja em suas sucessivas versões, seja, ainda, nos diversos lugares sociais da fala, fundado na pluralidade étnico-racial e na fraternidade.

Por fim, temos "A estampa originária da dependência", ensaio em que temos a leitura crítica da Carta, de Pero Vaz de Caminha. O relato da primeira missa mostra os elementos que compõem a história colonial: os portugueses e os nativos. E a descrição do prosseguimento da missa instaura uma representação dos nativos que se dá pelo recorte da sua imagem fixada: pacíficos, atentos, reverentes, integrados e submetidos ao fascínio do ritual civilizado. A autora aponta a primeira missa como a protocena da identidade histórica e cultural brasileira, haja vista que os elementos de nacionalidade desde sempre são os mesmos ali representados, e as significações imaginárias decorrentes não perdem o seu vigor. E, assim, também se encontra em 
pleno empreendimento nacionalista dos intelectuais brasileiros oitocentistas, que, a partir do ideal e da necessidade de representar a nacionalidade, voltam-se para aquela anterior representação, repetindo os mesmos traços, ainda que numa outra forma. Desse quadro, a autora parte para a versão modernista da identidade cultural e para reflexões comparativas entre as dimensões do estético-literário e histórico-social quanto à apreciação crítica recente da identidade cultural brasileira.

Ao fim da leitura desse volume de ensaios, a proposição de uma perspectiva crítica baseada em elementos de um passado distante se mostrou capaz de projetar interpretações diferenciadas e redimensionadas às circunstâncias da contemporaneidade, possibilitando novas expectativas em relação a paradigmas que se tomavam por consolidados. Destacaram-se ao longo dos ensaios formulações teóricas próprias vislumbradas por meio da compreensão dos traços sucessivamente repetidos em exemplares do acervo literário brasileiro que representam o imaginário colonizador institucionalizante e suas decorrências no simbólico instituído. Ao trazer à tona o mal-estar de uma "certa" dependência cultural, a autora trabalha os paradoxos desse imaginário para desconstruir e reconstruir a multifacetada identidade cultural brasileira, por um viés sempre aberto a novas e infindáveis leituras.

\section{Referência Bibliográfica}

CUNHA, Eneida Leal. Estampas do imaginário: literatura, história e identidade cultural. Belo Horizonte: UFMG, 2006. 
